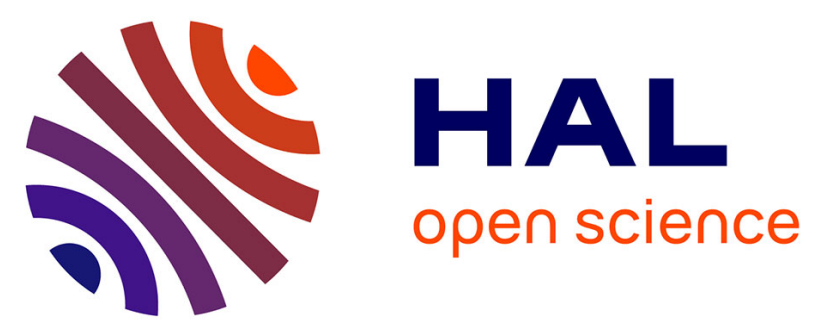

\title{
Technocracy to Democracy Knowledge Transfer Using Social Media and Reputation Management
} Aggeliki Androutsopoulou, Yannis Charalabidis, Euripidis Loukis

\section{To cite this version:}

Aggeliki Androutsopoulou, Yannis Charalabidis, Euripidis Loukis. Technocracy to Democracy Knowledge Transfer Using Social Media and Reputation Management. 9th International Conference on Electronic Participation (ePart), Sep 2017, St. Petersburg, Russia. pp.75-86, 10.1007/978-3-31964322-9_7. hal-01703334

\section{HAL Id: hal-01703334 \\ https://hal.inria.fr/hal-01703334}

Submitted on 7 Feb 2018

HAL is a multi-disciplinary open access archive for the deposit and dissemination of scientific research documents, whether they are published or not. The documents may come from teaching and research institutions in France or abroad, or from public or private research centers.
L'archive ouverte pluridisciplinaire HAL, est destinée au dépôt et à la diffusion de documents scientifiques de niveau recherche, publiés ou non, émanant des établissements d'enseignement et de recherche français ou étrangers, des laboratoires publics ou privés. 


\title{
Technocracy to Democracy Knowledge Transfer Using Social Media and Reputation Management
}

\author{
Aggeliki Androutsopoulou ${ }^{10000-0002-9059-0707]}$, Yannis Charalabidis ${ }^{1}$, \\ and Euripidis Loukis ${ }^{1[0000-0002-5932-4128]}$ \\ ${ }^{1}$ Department of Information and Communication Systems Engineering, \\ University of the Aegean, Samos Greece \\ $\{$ ag.andr, yannisx, eloukis\} @aegean.gr
}

\begin{abstract}
Previous political sciences research has highlighted the importance of both 'democracy' (democratic processes and consultation with stakeholder groups) and 'technocracy' (specialized knowledge of experts) as main foundations for the development of effective public policies, and the need for balance as well as interaction between them. The use of information and communication technologies (ICT) for supporting this exchange can be highly beneficial. Our paper makes a contribution in this direction, by evaluating an ICT-based 'expertsourcing' method that has been developed for supporting the transfer of knowledge from 'technocracy' (i.e. knowledgeable experts) to 'democracy' (i.e. participants of the democratic processes, such as citizens' representatives, elected officials and various public policies' stakeholder groups). This method exploits policy-related content that has already been published by experts in numerous social media, adopting a selective approach (filtering this content in order to extract the highest quality parts of it that have been authored by the most knowledgeable experts) based on reputation management techniques. From the evaluation of this ICT-based 'expert-sourcing' method useful conclusions have been drawn concerning its strengths and weaknesses, as well as directions for the improvement of it and the enhancement of its value.
\end{abstract}

Keywords: Social Media, Reputation Management, Expert-sourcing, Democracy, Technocracy

\section{Introduction}

Previous political sciences research has highlighted the importance of both 'democracy' (democratic processes and consultation with stakeholder groups) and 'technocracy' (specialized knowledge of experts) for the development of effective public policies, and the need for balance as well as interaction between them [27, 11, 13, 28]. This research has concluded first that the domination of one of them over the other can have negative impact on the quality and effectiveness of the resulting public policies; and second, that 
each of them needs inputs from the other, so extensive exchange of knowledge between them is required. The use of information and communication technologies (ICT) for supporting this exchange can be highly beneficial. Previous research in the information systems (IS) domain has revealed that ICT can significantly support and increase the effectiveness of knowledge transfer [17]. However, there has been a lack of research on ICT-based support of knowledge transfer in the above context, between 'technocracy' and 'democracy', despite its criticality for public policy development. So extensive research is required for the development of ICT-based methods that can effectively support the effective exchange of policy related knowledge between 'technocracy' and 'democracy', as well as for their evaluation, in order to identify their strengths and weaknesses, and also make improvements of them in order to enhance their value, so that finally high levels of maturity can be achieved in this novel area.

Our paper makes a contribution in this direction, by evaluating an ICT-based 'expert-sourcing' method that has been developed for supporting the transfer of knowledge from 'technocracy' (i.e. knowledgeable experts) to 'democracy' (i.e. participants of the democratic processes, such as citizens' representatives, elected officials and various stakeholder groups), in order to identify its strengths and weaknesses, as well as value enhancing improvements of it. This method has been developed within the European research project 'EU-Community' (project.eucommunity.eu/), which has been partially funded by the 'ICT for Governance and Policy Modelling' research initiative of the European Commission. It exploits policy-related content that has already been published by experts in numerous social media, adopting a selective approach: it filters this content, in order to extract the highest quality parts of it that have been authored by the most knowledgeable experts, based on reputation management techniques. A comprehensive description of this method is provided in [1], however for the sake of completeness of this paper an outline of it is presented in section 3 .

So, the research objectives of this paper are:

i) to evaluate the above method in order to identify its strengths and weaknesses,

ii) as well as to make improvements of it that can enhance its value.

The paper is structured in six sections. In the following section 2 the background of our research is presented. The abovementioned ICT-based expert-sourcing method is outlined in section 3 , while the data and method of our study are described in section 4 . Then the results of the evaluation are presented in section 5. Finally, in section 6 the conclusions are summarized and future research directions are proposed.

\section{Background}

\subsection{Democracy vs Technocracy}

There has been considerable political sciences research, as well as political debate, concerning the relationships between public policies formulation, democracy (i.e. the role of democratic processes and consultations with stakeholder groups) and technocracy (i.e. the role of knowledgeable experts). On one hand the development of the 'participative democracy' ideas have resulted in a growing involvement of stakeholder groups in the formulation of public policies [2, 21, 30-31, 24-25]. In [31] public participation 
is defined as 'the practice of consulting and involving members of the public in the agenda-setting, decision-making and policy forming activities of organizations or institutions responsible for policy development'. Public participation constitutes a move away from an 'elitist model' of public policy development, in which managers and experts are the basic source of policies, towards a new more 'democratic model', in which the citizens have an active role and voice in policies' formulation. It should be noted that the development of the 'participatory democracy' does not aim at the replacement of the existing 'representative democracy' (and its institutions, such as the Parliaments and other representative institutions, and the elected officials), but on the contrary at the enhancement and revitalization of it. However, throughout the public participation literature it is emphasized that in order to be successful it is necessary the participating stakeholders to be sufficiently informed about the complex social problems under discussion, and the existing options for addressing them (various alternative interventions that government can undertake for this purpose, as well as advantages and disadvantages of them, short and long term impacts, etc.). The increasing complexity of the problems and the needs of modern societies have increased the importance of knowledge and expertise for the design and implementation of relevant public policies. This has led to the establishment and growing influence of various expert bodies (having various forms, ranging from committees to separate organizations, such as economic institutes), in both government agencies competent for the formulation of public policies, and also the other public policy stakeholders (e.g. associations of professions, labor unions and other interest groups). These expert bodies have become today highly important for and influential on the formulation of public policies, and this is termed 'technocracy' [6, 11, 14-15, 27-28]. So today it is widely recognized that the two fundamental and mutually complementary foundations of public policy making are democracy (representative institutions and elected officials) and technocracy.

Political sciences research in this area has highlighted the need of balance as well as relationship, interaction and exchange of knowledge between them, as each of them needs inputs from the other, while both make significant but different contributions to the design of public policies. In particular, participants in the democratic processes (citizens' representatives, elected officials, various stakeholder groups) need extensive knowledge and expertise on the social problems they are dealing with, while the lack of them can have quite negative impacts on the quality and effectiveness of the formulated public policies [11,32]. At the same time experts dealing with important social problems often tend to 'de-politicize' them [11, 13-14], or give low priority to important aspects of public policies, such as employment generation, poverty eradication, inclusive social protection, etc. [32]; in order to reduce these negative tendencies, experts need inputs from the democratic political process, concerning diverse values and concerns of different stakeholder groups, as well as their diverse perspectives, approaches and ideologies. So, Gilley [14] argues that 'democratic sovereignty and technocratic expertise must coexist', with each of them being necessary conditions for the other, and concludes that 'a healthy democracy requires a healthy technocracy and vice versa'.

The ICT can be very useful for supporting the above required interaction and exchange of knowledge between these two important foundations of modern public policy 
making, the 'democracy' and the 'technocracy'. However, as mentioned in the Introduction, limited research has been conducted in this direction. Our paper contributes to filling this research gap, by analyzing and evaluating an ICT-based method that supports the transfer of knowledge from the latter to the former, and identifying its strengths and weaknesses, and proposing improvements for increasing its value.

\subsection{Government Citizen-Sourcing}

The public sector, motivated by the multiple 'success stories' of crowdsourcing in the private sector $[4-5,16]$, has started moving to this direction as well, using the ICT, and especially the social media, in order to exploit 'collective wisdom', giving rise to the gradual development of 'citizen-sourcing' [12, 18, 20, 22-23, 26]. Most of these first citizen-sourcing initiatives follow the 'active citizen-sourcing' paradigm, in which government agencies' web-sites or social media accounts are used in order to pose a particular social problem or public policy (existing or under development), and solicit relevant information, knowledge, opinions and ideas from the general public [7, 12, 22]. Recently, there has been some research interest in the 'passive citizen-sourcing' paradigm, which aims to exploit policy-related content that has been generated by citizens freely, without any direct stimulation or direction by government, in various external (i.e. not belonging to government agencies) web-sites or social media, such as political fora, news web-sites, political blogs, Facebook, Twitter, etc. accounts; the analysis of this content can provide useful information, knowledge and ideas concerning important social problems and public policies $[3,8,20]$

However, a common characteristic of the first citizen-sourcing initiatives is that they aim to collect policy relevant knowledge and perceptions from the general public, and this has resulted in outcomes of varying quality levels. So, it would be useful, additionally to attempt collect relevant knowledge from experts as well, and this leads to the development of the new paradigm of 'expert-sourcing'; this paper contributes to the development of it, by analysing and evaluating an ICT-based passive expert-sourcing method (outlined in the following section 3), and identifying its strengths, weaknesses, as well as valuable improvements of it.

\section{An ICT-based Passive Expert-sourcing Method}

As mentioned previously, an advanced passive ICT-based expert-sourcing method has been developed in the European research project 'EU-Community' (see project.eucommunity.eu/)'; a comprehensive description of it is provided in [1], however for the sake of completeness of this paper an outline of it is presented in this section. It is based on the automated retrieval from multiple online sources at regular time intervals of information about experts on various policy related topics, as well as relevant online texts and postings already published by such experts in multiple social media and web-sites; so it does not require from experts to create new content (which would be problematic as usually they are under pressure of time), conducting a selective 'passive' crowd- 
sourcing $[3,8,20]$. The retrieved content is filtered, in order to extract the highest quality parts of it that have been authored by the most knowledgeable experts, using reputation management techniques, in combination with text/opinion mining. This is a novel feature of this method in comparison with previous government citizen-sourcing methods, which target the general public, aiming to collect policy relevant knowledge and perceptions from it [e.g. 7, 8, 12, 19, 20].

In particular, one component of the ICT platform supporting the application of this method maintains a directory of profiles of individuals possessing high levels of knowledge, expertise and credibility in one or more predefined topics related with EU policies. Data about these individuals are collected and included in the corresponding database automatically by the crawlers sub-component (that crawls at regular time intervals numerous external sources, which can be pre-defined websites (e.g. Euractiv.com, EUR-Lex, Europa Whoiswho directory, RSS Feeds, blogs and news sites) and social media accounts (e.g. LinkedIn, Twitter)), or even can be entered manually by interested individuals (self-registration - in this case a validation by the system administrators follows). Furthermore, this component provides rankings of the expert profiles on one or more topics, based on their relevant expertise, through 'reputation scores' calculated by a reputation management sub-component. For this purpose is used a synthetic algorithm based on the following criteria (having different weights): selfevaluation; peer-assessment (based on endorsements from other experts); 'business card' reputation (based on the reputation ranking of the organization he works in, or committees he belongs to, and his/her position in it); documents assessments (results of his/her authored documents' assessments by their readers); network value (level of influence as the sum of his/her network connections); proximity trust (degree of connection in social media); past rankings (taking into account reputation rankings in previous months; offline reputation (manually added for persons with no online presence). This component provides multiple experts' search capabilities, e.g. by name, country or EU policy or topic, and returns experts found in its database in descending reputation score order (i.e. showing first the most reputable ones).

Another component of the ICT platform supporting the application of this method maintains a database of relevant documents concerning the above predefined policy related topics of interest. For this purpose it crawls at regular time intervals various external sources of content related to EU policies, such as relevant blogs, websites of EU institutions (e.g. European Commission), relevant media (such as EurActiv, European Voice, EU Observer) and various EU policy stakeholders' websites (such as various business and professional associations and NGOs' portals), and also social media accounts, where relevant positions and opinions are published, and updates with new content the corresponding documents' database. These documents (blog posts, social media content, online comments, word/pdf documents, web pages, etc.) are first correlated with the most relevant policy topic and subtopics (one document may match more than one subtopics), and possibly linked to one or more authors of the above individual experts' database. Next, for each document its quality is rated with respect to the above policy topic/subtopic(s), using an algorithm based on the following criteria: author (his/her credibility ranking for the specific topic/subtopic as provided by the reputation 
management module described above); ratings by other experts submitted in the platform, with respect to quality, accuracy, value, relevance and timeliness (which are weighted based on the reputation of the individuals who provide them). Also, these documents undergo sophisticated processing using text/opinion mining and sentiment classification techniques, in order to assess their sentiment (positive, negative or neutral). These documents are structured around 'policy processes' (as policy process can be modelled any prospective, ongoing or completed E.U. legislative procedure, or any political debate in general), which can be created by system users. Furthermore, this component provides a timeline visualization (see Fig. 1), which shows the main documents (based on quality ratings, as assessed using the above algorithm) associated with a policy process selected by the user in a temporal order; different types of documents are represented by different shapes, while the sizes of the shapes reflecting their quality). A complete view of all documents associated with the process is provided through a tabular visualization provided by the component.

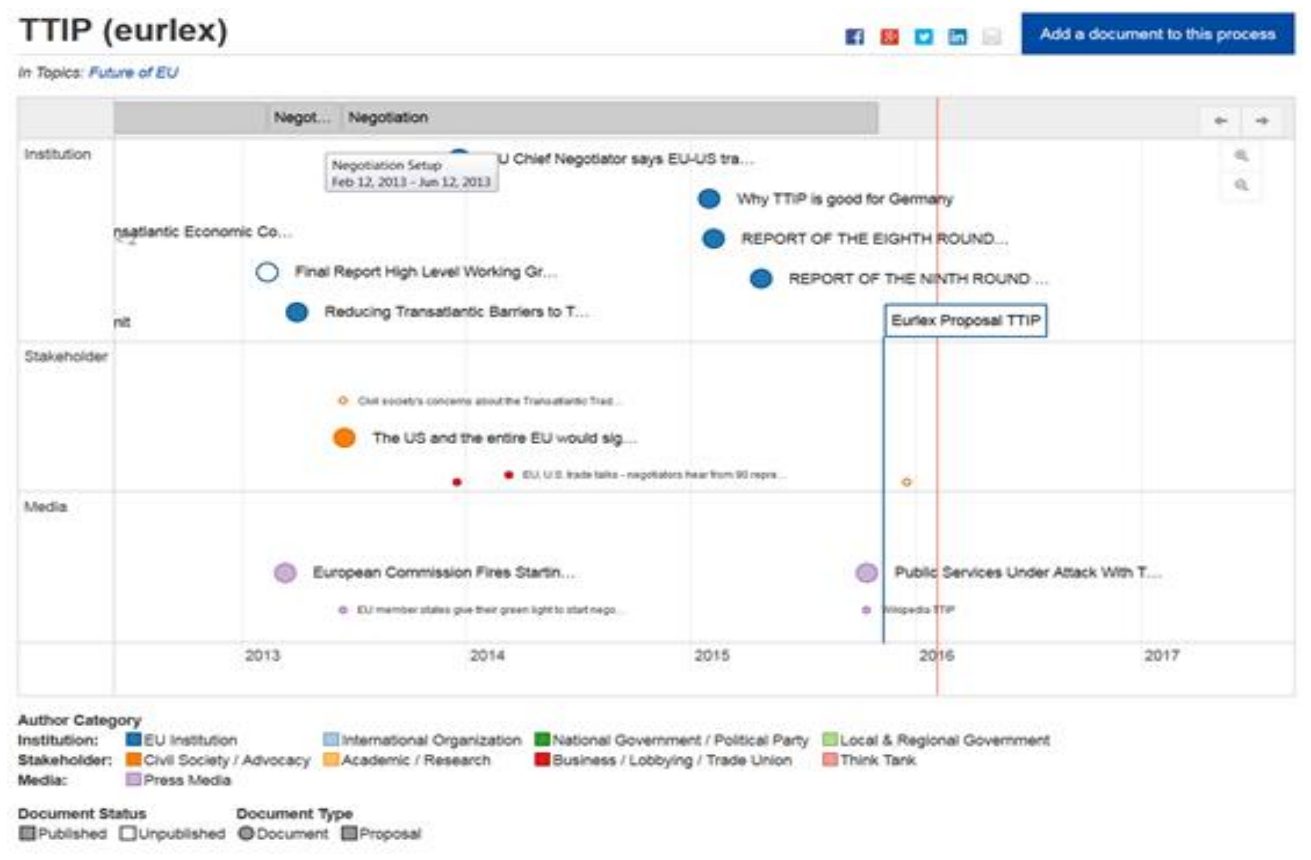

Fig. 1. Documents' timeline visualization

\section{Data and Method}

For the evaluation of the ICT-based passive expert-sourcing method outlined in previous section 3 three pilot applications of it have been conducted, concerning three important EU policy related topics agreed among the 'EU-Community' project partners: Innovation and Entrepreneurship, Energy Union and Future of the European EU. In particular, for each of them numerous online sources were crawled, in order to retrieve 
and store expert profiles, and also various types of relevant documents (e.g. blog posts, social media content, online comments, word/pdf documents, web pages, etc.); then they were all processed as described in the previous section. Next, five interviews were conducted with Members of the Greek Parliament, with each of them having a duration of about 1.5 hour. They included initially a presentation of this ICT-based passive expert-sourcing method, its supporting ICT platform, as well as the abovementioned three pilot applications; then the interviewees were asked to use the platform in order to perform searches of experts and documents concerning the above three topics, examine and understand the results' visualizations, and then see in more detail document-level information and content, with our assistance.

In order to collect evaluation data from the interviewees about this ICT-based passive expert-sourcing method we used mainly qualitative techniques, however complemented by quantitative ones. According to relevant literature [9, 29], the qualitative techniques allow a more in-depth examination of a social phenomenon, and enable the generation of deeper knowledge about it, its positive and negative aspects as well as a deeper explanation of them ('how' and 'why'). However, the quantitative techniques offer the advantage of enabling the summarization of positive and negative aspects into a few numbers, which make it easier to draw conclusions.

For these reasons, in order to combine the abovementioned advantages of the qualitative and the quantitative techniques, in each of these interviews initially we conducted a qualitative in depth discussion about the usefulness of this method from the technocracy to democracy knowledge transfer perspective:

i) for the acquisition/collection of high quality expert knowledge concerning a specific public policy (existing, under development or proposed) we are interested in;

ii) for the transfer of policy related knowledge from experts to the participants of the democratic processes (such as members of parliaments and their assistants, representatives of various policy stakeholder groups, etc.);

iii) and for assisting the above participants of the democratic processes for having a better, more substantial and constructive participation in public policy debates;

The above qualitative discussions were recorded, and then transcribed and coded manually using an open coding approach [9].

Then we asked the interviewees to fill a short evaluation questionnaire, which included three questions corresponding to the above three discussion topics; they were converted to positive statements, and the interviewees were asked to provide the degree of their agreement/disagreement with each of them in a five-levels scale ( $1=$ strongly disagree, 2 = disagree, $3=$ neutral, $4=$ agree, $5=$ strongly agree), as a summary/aggregation of all the positives and negatives they mentioned in our discussion.

\section{Results}

In Table 1 we can see the results of the processing of the quantitative evaluation data collected through the questionnaire; for each question are shown the frequencies/numbers of the responses 'strongly disagree' (SD), 'disagree'(D), 'neutral'(N), 'agree' (A) and 'strongly agree' (SA) respectively. 
Table 1. Results of processing the quantitative evaluation data collected through the questionnaire (frequencies of interviewees' responses)

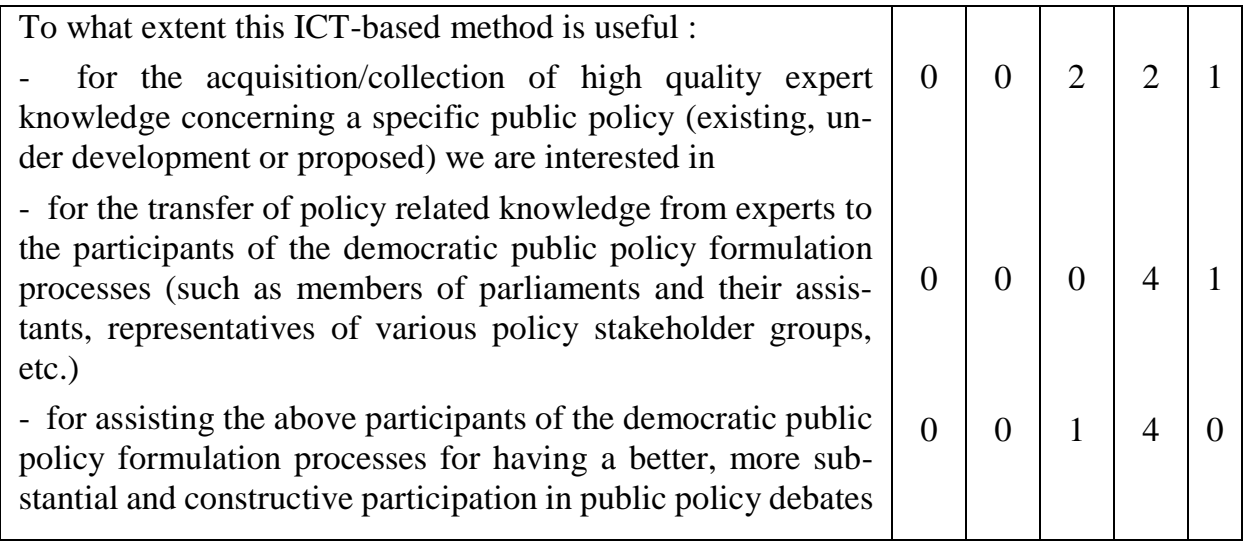

From the above Table we can see that there is a medium to high level of agreement concerning the usefulness of this ICT-based method for the acquisition of high quality expert knowledge concerning a particular public policy, as 2 out of the 5 interviewees agree on this, 1 strongly agrees, and the remaining two are neutral. However, most of the interviewees agree (4), and one strongly agrees, that this ICT-based method is useful for its main objective: the transfer of policy related knowledge from experts to the participants of the democratic processes. Furthermore, most of the interviewees agree (4), and one is neutral, that this method can assist the above participants of the democratic public policy formulation processes for having a better, more substantial and constructive participation and contribution in public policy debates.

In the qualitative in depth discussions it has been mentioned by the interviewees that the policy related documents provided by the platform seem to be of high quality, authored by knowledgeable experts, and contain useful expert knowledge on these specific important policy related topics, so this is an important strength. They consider this method as a useful tool that could complement other mechanisms they already use for finding relevant information and knowledge on public policies under discussion; however they would like, beyond the automated identification of experts and documents, as well as their rating and ranking, which are performed automatically by the system, some human presence, in order to double check and curate this content. As characteristically expressed by one of the interviewees "My biggest concern is to what extent the information and knowledge I get from the system is checked and reliable, so it can save me from the effort of checking it myself again and again. My experience shows that there is much fake information, so we have every day to ensure that information is coming from real experts". Others suggested that the proposed platform could be used as an entry point of reference, from where they could go to the original sources to cross-check the reliability of the content.

The first weakness mentioned by the interviewees in the qualitative in depth discussions is that the knowledge contained in the documents provided per topic by the system is not directly accessible, as the user has to read these documents (most of them being 
rather lengthy) in order to extract this knowledge; it has been mentioned by one of the interviewees that "a policy analysis has to be read in detail in order for someone to gain the picture". So it was suggested that it would be highly beneficial to make further 'deeper' processing of these documents, in order to automatically extract the relevant knowledge they contain, instead of the user having to do this manually. A first step in this direction might be to extract the main terms mentioned in each document, as well as in groups of related documents, using advanced methods of text/opinion miming, and then presenting a visualization of the results possibly in the form of 'word cloud' (with the most frequently used words shown bigger). Some interviewees mentioned another issue of the algorithms used for assessing the reputation of experts and the quality and relevance of the documents: they take into account factors concerning authors' social media presence and connections, 'business card' reputation (i.e. being part of highly reputable organizations or committees), and also documents' ratings by users (such as quality, accuracy, value and relevance ratings). Taking into account the existing 'populism' in the political debates in general, many actors (mainly politicians, but also sometimes scientists as well) tend to support popular and 'pleasant' positions, instead of less pleasant but more beneficial ones in the long run; so 'popular' does not necessary mean scientifically sound. This means that a popular politician would probably be assigned high rating and ranking for a topic by our algorithms, although he/she may not be really knowledgeable about it, by being highly popular (having numerous social media connections, and receiving high assessments for the documents he/she authors), and/or by being a member in important institutional committees. One of our interviewees mentioned "I can see institutional experts in the tool, who claim expertise because they are associated with a particular committee or a position, but to me these do not imply that they are experts in the topic". In order to address this issue two main improvements of our method have been proposed: i) the weights for the popularity and the 'business card' related factors should not be very high, so that they do not influence too much the ratings of experts and documents; ii) a more radical intervention might be to distinguish between two classes of experts: the politicians-experts and the scientists/academics - experts, with each of them having different rankings, criteria and weights; the same applies for the documents: there should be a differentiation between politicians-experts' documents and scientists/academics - experts' documents, having different criteria and weights for assessing the quality of these two types of documents.

It was also emphasized that the trustworthiness of the results depends on the size and the diversity of the community that will be built around this ICT platform. This community will result in a large number of diverse multi-perspective policy related documents; furthermore it will provide large numbers of diverse assessments of the documents identified in the crawled sources, resulting in higher quality of ratings and rankings of the documents, and through them higher quality ratings and rankings of their authors. It has been mentioned by one of the interviewees that "If sufficient number of experts exists in the database, I would trust more the results concerning credible experts and documents; it is important a 'critical mass' to be achieved on a policy topic, with respect to experts and documents, so that it is covered to a sufficient extent". Therefore it is important to build and maintain an extensive high quality and diverse community around this ICT platform. 
Finally, another remark concerned an important type of useful policy related content not captured by our method: speeches in Parliaments (or other bodies of citizens' representatives, such as regional or municipal councils), by politicians and invited experts, which are not recorded in minutes. It has been argued that such speeches contain useful high quality information and knowledge on the debated social problems and public policies; however, some of this content is not recorded in the minutes, but it is recorded as audio or video. So a very useful extension of our method would be to add capabilities of processing and analyzing such multimedia content.

\section{Conclusions}

In the previous sections of this paper has been presented an evaluation of an ICT-based 'expert-sourcing' method, aiming to support the transfer of knowledge from 'technocracy' (i.e. knowledgeable experts) to 'democracy' (i.e. participants of the democratic processes, such as citizens' representatives, elected officials and various public policies' stakeholder groups). This evaluation has been based mainly on qualitative data, complemented by quantitative ones, collected though five interviews with Members of the Greek Parliament.

Our results are in general encouraging. The interviewees perceive a medium to high level of usefulness of this method for the acquisition of high quality experts' knowledge concerning social problems and public policies we are interested in. At the same time they identified some weaknesses of the method, which have led to proposals for improvements of it that can significantly enhance its usefulness and value:

- The most important of them is to proceed to a 'deeper' processing of the text of the policy related experts' documents provided by this method, in order to extract the knowledge they contain (so that the users do not have to do this manually, by reading lengthy documents).

- Another important improvement might be the discrimination between two classes of experts: the politicians-experts and the scientists/academics - experts, with each of them having different rankings, criteria and weights; and also the differentiation between politicians-experts' documents and scientists/academics - experts' documents. - Also, in the experts' and documents' rating algorithms of this method are required appropriate settings of the weights for the social media presence, connections, popularity and 'business card' related factors, so that they do not influence too much the ratings of experts and documents.

- Human intervention will be useful for double-checking and curating the automatically collected content (through crawlers), in order to improve the reliability of the results.

- Finally technical capabilities should be enriched, enabling the processing and analysing of not only textual content, but also multimedia as well.

In general, taking into account both the strengths and the weaknesses of this method, it is perceived as a highly useful mechanism for the transfer of policy related knowledge from experts to the participants of the democratic public policy formulation processes (such as members of parliaments and their assistants, representatives of various policy 
stakeholder groups, etc.); and also for providing assistance to the latter in order to have a better, more substantial and constructive participation in public policy debates.

Further research is required for more extensive evaluation of the specific ICT-based technocracy to democracy knowledge transfer method by different groups of participants in the democratic processes (not only by Members of Parliaments, but also by citizens' representatives at lower administrative levels, such as regional, municipal, etc., as well as other policy stakeholders, such as associations of professions, labor unions and other interest groups). Also evaluation of it should be conducted from more perspectives of the political and management sciences, in order to develop a wider base of knowledge about different dimensions of advantages/strengths and disadvantages/weaknesses of this method. Furthermore, research is required towards the abovementioned improvements proposed by the interviewees. Additional research should also be conducted concerning the exploitation of ICT for the transfer of knowledge in the opposite direction (which is equally important - see [14], [15], [28]): from the democratic processes towards the experts/technocracy (concerning diverse needs, values and concerns of different stakeholder groups on the particular social problem or public policy the experts are dealing with).

\section{References}

1. Androutsopoulou, A., Mureddu, F., Loukis, E., Charalabidis, Y.: "Passive Expert-Sourcing for Policy Making in the European Union", In: Proceedings of IFIP EGOV-EPART 2016 Conference, Guimarães, Portugal (2016).

2. Barber, B.: Strong Democracy. University of California Press: Berkeley (1984).

3. Bekkers, V., Edwards, A., de Kool, D.: Social media monitoring: Responsive governance in the shadow of surveillance? Government Information Quarterly 30(4), 335-342 (2013).

4. Brabham, D.: Crowdsourcing as a Model for Problem Solving: An Introduction and Cases. Convergence: The International Journal of Research into New Media Technologies 14 (1), 75-90 (2008)

5. Brabham, D..: Crowdsourcing. Cambridge, MA: The MIT Press (2013).

6. Brown, M..: Science in Democracy: Expertise, Institutions, and Representation. Cambridge, MA: MIT Press (2009).

7. Charalabidis, Y., Loukis, E.: Participative Public Policy Making Through Multiple Social Media Platforms Utilization. International Journal of Electronic Government Research 8(3), 78-97 (2012).

8. Charalabidis, Y., Loukis, E., Androutsopoulou, A., Karkaletsis, V., Triantafillou, A.: Passive Crowdsourcing in Government Using Social Media. Transforming Government: People, Process and Policy (8)2, 283-308 (2014).

9. Cooper, D., Schindler, P.: Business Research Methods. 12th Edition. McGraw-Hill: New York, USA (2013).

10. Davis, F.: Perceived usefulness, perceived ease of use, and user acceptance of information technology. MIS Quarterly 13(3), 319-339 (1989).

11. Esmark, A.: Maybe It Is Time to Rediscover Technocracy? - An Old Framework for a New Analysis of Administrative Reforms in the Governance Era. Journal of Public Administration Research And Theory (2016) (in-press). 
12. Ferro, E., Loukis, E., Charalabidis, Y., Osella, M.: Policy Making 2.0: From Theory to Practice. Government Information Quarterly 30(4), 359-368 (2013).

13. Fischer, F.: Technocracy and the Politics of Expertise. London: Sage (1990).

14. Gilley, B.: Technocracy and democracy as spheres of justice in public policy". Policy Sciences (2016) (in-press).

15. Harcourt, A., Radaelli C.: Limits to EU technocratic regulation? European Journal of Political Research 35, 107-122 (1999).

16. Hossain, M., Kauranen, I.: Crowdsourcing: a comprehensive literature review. Strategic Outsourcing: An International Journal, comprehensive literature review, Strategic Outsourcing: An International Journal 8(1), 2-22 (2015).

17. Iyengar, K., Sweeney, R. , Montealegre, R.: Information Technology Use as a Learning Mechanism: The Impact of IT Use on Knowledge Transfer Effectiveness, Absorp-tive Capacity, and Franchisee Performance. MIS Quarterly 39(3), 615-641 (2015).

18. Linders, D.: From e-government to we-government: Defining a typology for citizen coproduction in the age of social media. Government Information Quarterly 29, 446-454 (2012).

19. Loukis, E., Charalabidis, Y., Androutsopoulou, A.: An Analysis of Multiple Social Media Consultations in the European Parliament from a Public Policy Perspective. European Conference on Information Systems (ECIS) 2014, Tel Aviv, Israel (2014).

20. Loukis, E., Charalabidis, Y., Androutsopoulou, A.: Promoting Open Innovation in the Public Sector Through Social Media Monitoring. Government Information Quarterly 34(1), 99-109 (2016).

21. Macpherson, C. B. (1977). The Life and Times of Liberal Democracy. Oxford University Press: London and New York (1977).

22. Mergel, I., Desouza, K. C.: Implementing Open Innovation in the Public Sector: The Case of Challenge.gov. Public Administration Review 73(6), 882-890 (2013).

23. Nam, T.: Suggesting frameworks of citizen-sourcing via Government 2.0. Government Information Quarterly 29, 12-20 (2012)

24. Organization for Economic Co-operation \& Development (OECD). Evaluating Public Participation in Policy Making. OECD: Paris (2005).

25. Organization for Economic Co-operation \& Development (OECD). Focus on Citizens: Public Engagement for Better Policy and Services - Policy Brief. OECD: Paris (2009).

26. Prpić, J., Taeihagh, A., Melton, J.: The Fundamentals of Policy Crowdsourcing. Policy \& Internet 7(3), 340-361(2015).

27. Radaelli, C. M.: The Role of Knowledge in the Policy Process. Journal of European Public Policy 2(2), 159-183 (1995).

28. Radaelli, C. M.: The Public Policy of the European Union: whither Politics of Expertise? Journal of European Public Policy 6(5), 757-774 (1999).

29. Ragin, C., Amoroso, L.: Constructing Social Research: The Unity and Diversity of Method 2nd Edition. Pine Forge Press - Sage Publications, California, USA (2011).

30. Rowe G., Frewer J..: Public Participation Methods: A Framework for Evaluation". Science, Technology \& Human Values 25(1), 3-29 (2000).

31. Rowe G., Frewer J.: Evaluating Public-Participation Exercises: A Research Agenda". Science, Technology \& Human Values 29(4), 512-557 (2004).

32. United Nations Research Institute for Social Development. Technocratic Policy Making and Democratic Accountability, UNRISD Research and Policy Brief no. 3, United Nations Research Institute for Social Development (UNRISD), Switzerland (2004). 